\title{
AVALIAÇÃO DO DESEMPENHO DE CENTRO DE SERVIÇOS COMPARTILHADOS: UM ESTUDO DE CASOS MÚLTIPLOS EM REDES VAREJISTAS
}

Jaline Riscado Da Silva

jaline.rs@hotmail.com

Suellen Miranda Barreto

suellenmbarreto@hotmail.com

Edson Terra Azevedo Filho

edsonterrafilho@gmail.com

Henrique Rego Monteiro da Hora

dahora@gmail.com

Helder Gomes Costa

hgc@pq.cnpq.br

\section{RESUMO}

Tendo em vista que empresas de todos os portes e dos mais variados setores vêm adotando o modelo de CSC, com o objetivo de prestar serviços de alta qualidade à empresa, com custos otimizados. $\mathrm{O}$ presente estudo tem por objetivo desenvolver uma metodologia que permita de maneira simplificada avaliar o nível de desempenho dos serviços prestados por Centro de Serviços Compartilhados (CSC). Embasando-se na literatura sobre as características dos CSCs, estruturou-se o arcabouço teórico do estudo e definiram-se os aspectos da análise. E por meio de estudos de caso múltiplos, a metodologia proposta foi aplicada em empresas do segmento do varejista, sendo entrevistados quatro colaboradores de nível tático das unidades pesquisadas. De acordo com a síntese dos resultados da pesquisa, pode ser verificado que os serviços compartilhados de tecnologia da informação e marketing foram avaliados como satisfatórios, entretanto a área de logística, recursos humanos e finanças foram considerados pouco satisfatórios. Evidenciou-se nessa pesquisa, que avaliação das atividades não-core, é uma prática fundamental para a gestão do Centro de Serviços Compartilhados.

Palavras-chave: Centro de serviços compartilhados (CSC), comércio varejista, serviços.

\section{ARBSTRACT}

Bearing in mind that companies of all sizes and from the most varied sectors have been adopting the CSC model, with the aim of offering high quality services to the company, with optimized costs. The present study aims to evaluate, in a simplified manner, the level of performance of the services provided by Shared Service Center (CSC). Basing on the literature about the characteristics of CSCs, the theoretical framework of the study was structured and the aspects of the analysis were defined. And through multiple case studies, the evaluation was conducted in the retailing business, where four tactical employees from searched units were interviewed. According to the synthesis of the search results, it can be verified that the shared services of information technology and marketing were evaluated as satisfactory, however the logistic area, the financial and human resources were considered little satisfactory. It became evident in this research that the evaluation of non-core activities is a key practice for managing the Shared Services Center.

Keywords: Shared Services Center (SSC), retailing business, services. 


\section{Introdução}

Empresas de todos os portes e dos mais variados setores vêm adotando o modelo de Centro de Serviços Compartilhados (CSC) na busca constante de competitividade, essas organizações tem buscado a otimização de seus processos, com o objetivo de prestar serviços de alta qualidade à empresa, com custos otimizados.

O CSC é a estratégia na qual diversas funções de negócios existentes são concentradas dentro de uma nova e semi-autônoma unidade de negócio, que tem uma estrutura gerencial designada para promover eficiência, geração de valor, redução de custos e melhoria nos serviços para clientes internos da empresa como se fosse um negócio competindo no mercado aberto (BERGERON, 2003, apud CUNHA, 2011).

De acordo com Gonçalves (2005), serviços compartilhados são parcerias entre executores de determinadas tarefas/atividades e clientes internos e externos, empresas nacionais ou multinacionais. Essa parceria é voltada para reorganização de atividades administrativas/financeiras, de recursos humanos, logística, tecnologia da informação e outras atividades, em que exista uma divisão de tarefas, ou seja, um compartilhamento de suas execuções.

A criação dos CSC tem orientado a reestruturação de grandes empresas no Brasil e no mundo e tem sido objeto de rápida disseminação e apropriação, com marcante incremento na adoção desses conceitos pelas grandes empresas, provocando mudanças funcionais relevantes nas organizações. Sua implantação e expansão estão em destaque na estratégia de muitas empresas focando a redução de custo através da eficiência (RAMOS, 2005).

A avaliação de desempenho do nível de serviços proporciona melhorias das atividades de apoio da empresa, como a padronização de processos e sistemas, exclusão de redundâncias, a centralização de informações, a redução dos ciclos de tempo das atividades, entre outros. Desta forma é possível que o CSC alcance a excelência operacional, de modo a prover serviços de suporte de alta qualidade a um custo competitivo.

Para conseguir identificar possíveis pontos críticos nos serviços prestados pelo Centro de Serviços Compartilhados (CSC), esta pesquisa será orientada pelo seguinte problema de investigação: "Como avaliar o nível de desempenho dos serviços executados pelo CSC, tanto em instituições públicas, quanto privadas"?

Responde-se ao questionamento da seguinte forma: As possíveis falhas e deficiências dos serviços realizados pelo CSC das unidades de negócio estudas no município de Campos dos Goytacazes precisam ser identificadas, e desta forma possibilitar aos seus gestores avaliar o desempenho das atividades executadas.

Assim sendo, este trabalho tem por objetivo avaliar o grau de desempenho dos serviços prestados por Centros de Serviços Compartilhados (CSC). 


\section{Revisão Bibliográfica}

\subsection{Histórico}

De acordo com Bangemann (2005 apud SOUZA; MELIM; MACEDO, 2012), a Ford Motors originou, juntamente com a General Electric, os serviços compartilhados no continente europeu, no início da década de 80, mais por acaso que por estratégia. O fato ocorreu na subsidiaria Finlandesa da Ford, quando uma elevada quantidade de colaboradores do financeiro se desligou da empresa simultaneamente. Devido a algumas dificuldades de reestruturação do quadro de funcionários, os serviços foram retomados por outra subsidiaria da Suécia de maneira remota.

De acordo com Schulman et al. (2001), o seu sucesso na área financeira fez com que essa prática começasse a ser aplicada em outras áreas, como tecnologia da informação, recursos humanos, jurídica e suprimentos.

A adesão ao compartilhamento de serviços por parte das empresas consideradas de grande porte na área em que atuam, comprova que este modelo de gestão vem se consolidando no âmbito empresarial, o que demonstra a relevância do tema no mundo corporativo. Empresas como a Ambev, uma das principais cervejarias do mundo, a Intel, a Hewlett-Packard, a General Eletric multinacionais americanas; e importantes empresas brasileiras como a Camargo Corrêa e o Grupo Votorantim, optaram por este tipo de estrutura organizacional mais simplificada e enxuta.

\subsection{Conceitos e definições}

O Centro de Serviços Compartilhados tem por finalidade agregar competitividade a empresa, gerando melhorias em suas operações internas e possibilitando maior foco nas suas atividades core business.

Segundo Schulman et al. (2001), os serviços compartilhados são:

A concentração dos recursos da empresa atuando com atividades, difundidas através da organização, a fim de servir a múltiplos parceiros internos, a baixo custo e com alto nível de serviços, com o objetivo comum de satisfazer os clientes externos e acrescentar valor à empresa.

Souza e Corrêa (2010) conceituam CSC como um modelo de organização e execução de atividades operacionais, onde uma área da corporação realiza serviços, a partir de um mesmo centro de atendimento, para diversas unidades da empresa. Entretanto, os serviços compartilhados não é apenas uma simples centralização de atividades de suporte realizadas sem identificar qual a real necessidade de determinado setor.

Ainda, para os autores, também não é uma simples terceirização de serviços, que tem por objetivo delegar a responsabilidade de atividades de apoio a terceiros. Um CSC é caracterizado como um centro orientado para as necessidades de seu cliente interno ou externo, visando qualidade e maximização da utilização de recursos.

Bergeron (2003, p. 3, apud CUNHA, 2011), complementa que nos Serviços Compartilhados:

Diversas funções de negócios existentes são concentradas dentro de uma nova e semi-autônoma unidade de negócio, que tem uma estrutura gerencial designada para promover eficiência, geração de valor, redução de custos e melhoria nos serviços para clientes internos da empresa como se fosse um negócio competindo no mercado aberto. 


\subsection{Principais motivações para implementar um CSC}

De acordo a Deloitte (2007), o objetivo da implementação dos centros de serviços compartilhados não é apenas a busca pela eficiência, mas também a excelência operacional. Entre as principais motivações estão:

- Padronizar processos e sistemas, centralizar informações;

- Diminuir custos operacionais através de economia de escala e escopo;

- Permitir às demais áreas focar em suas atividades primárias;

- Possibilitar às organizações agilidade nas novas aquisições;

- Melhorar o estabelecimento de controles e compliance.

Já para Affonso (2010), as motivações do compartilhamento de serviços são:

- Economia de escala, padronização dos processos, exclusão de redundâncias;

- Desenvolvimento da expertise entre as unidades de negócio, com o objetivo de conceber melhoria na qualidade dos serviços;

- Definição dos níveis de serviços e ênfase na qualidade dos mesmos;

- Melhoria na gestão dos custos, referentes a atividades de apoio;

- Liberação dos gestores das unidades de negócio, para focalizar o core business da organização.

\subsection{Desvantagens e pontos críticos do CSC}

Em contraponto das vantagens para a adoção do CSC, para Silva e Pereira (2004), a implantação de um centro de serviços compartilhados gera oposições dentro da empresa. Esta resistência surge porque para muitos, especialmente os gerentes de unidades de negócios, tem o sabor de centralização e controle da empresa. Estes fatores provocam uma mudança cultural nas empresas que implantam os serviços e ao mesmo tempo geram um desafio para que os benefícios possam ser alcançados.

De acordo com Cunha (2011), depois de compreendidos as vantagens e desvantagens da implantação de um CSC, pode-se sintetizar essas principais variáveis influentes no Quadro 1: 


\begin{tabular}{|c|c|}
\hline Vantagens provenientes do CSC & Desvantagens provenientes do CSC \\
\hline $\begin{array}{l}\text { Redução de custos } \\
\text { a) Aumento da produtividade } \\
\text { - } \quad \text { Eliminação da realização de tarefas repetidas } \\
\text { - Melhor eficiência nos processos } \\
\text { - } \quad \text { Redução dos ciclos de tempo das atividades } \\
\text { - Melhor coordenação da cadeia de suprimentos } \\
\text { b) Economias de escala } \\
\text { c) Economias de escopo } \\
\text { d) Melhor poder de negociação: preço e prazo } \\
\text { e) Redução de custos com tecnologia } \\
\text { f) Redução de custos com salários }\end{array}$ & $\begin{array}{l}\text { Possibilidade de não aceitação e resistência à uma nova unidade } \\
\text { de CSC } \\
\text { a) Mudanças culturais } \\
\text { b) Mudanças processuais } \\
\text { c) Mudanças tecnológicas } \\
\text { d) Tempo de adaptação ao CSC alto }\end{array}$ \\
\hline $\begin{array}{l}\text { Foco do CSC nas atividades não-core } \\
\text { a) Foco da matriz nas atividades estratégicas e core } \\
\text { b) Geração de especialização local } \\
\text { c) Criação de uma base de expertise e de um ambiente de } \\
\text { aprendizado para o conhecimento específico das atividades não- } \\
\text { core }\end{array}$ & $\begin{array}{l}\text { Problemas específicos no gerenciamento de pessoas } \\
\text { a) Pouca perspectiva dos funcionários em relação a um plano de } \\
\text { carreira interno ao CSC } \\
\text { b) Geração de tédio dos empregados em tarefas repetitivas }\end{array}$ \\
\hline $\begin{array}{l}\text { Padronização } \\
\text { a) Aumento do controle } \\
\text { b) Redução de risco transacional } \\
\text { c) Maior previsibilidade dos custos }\end{array}$ & Baixo nível de geração de novos conhecimentos \\
\hline $\begin{array}{l}\text { Preocupação com a satisfação dos clientes (demais unidades } \\
\text { organizacionais) na realização das atividades } \\
\text { a) Maior qualidade do serviço }\end{array}$ & $\begin{array}{l}\text { Localização distante } \\
\text { a) Relações de negócios enfraquecidas } \\
\text { b) Comunicação } \\
\text { c) Controle }\end{array}$ \\
\hline $\begin{array}{l}\text { Possibilidade de rendimentos extras e de aumento de capital de } \\
\text { giro }\end{array}$ & Interfaces \\
\hline & $\begin{array}{l}\text { Dispêndio de custos iniciais } \\
\text { a) Infra-estrutura }\end{array}$ \\
\hline
\end{tabular}

Quadro 1: Principais vantagens e desvantagens do CSC. Fonte: Cunha (2011).

\subsection{CSC versus Outsourcing}

Segundo Cunha (2011), é importante ressaltar, que a escolha em se implantar um CSC não envolve meramente a confrontação de suas vantagens e desvantagens, mas também, a comparação relativa do CSC com outras possibilidades de estruturas para a realização das atividades de apoio. Uma das grandes comparações reside na escolha entre o CSC e o outsourcing. De fato, muito se confunde entre essas duas alternativas. Isso porque por hora elas se entrelaçam em seus significados e conceitos, por hora, elas mantêm suas discrepâncias.

Para Ramos (2005), os Serviços Compartilhados buscam obter os benefícios da terceirização, tais como flexibilidade, foco e economia de escala, suprimindo seus principais riscos, como perda de conhecimento e do poder de execução, descontrole dos custos e do risco de descumprimento. Mas existem, também, alguns pontos negativos como altos investimentos em tempo e dinheiro e forte mudança organizacional. 
Já para Schulman et al. (2001), empresa que vendem serviços terceirizados sempre recuperam os custos, significado que é barato entrar na terceirização, mas quase sempre caro mantê-la pelo tempo todo.

Wang e Wang (2007 apud CUNHA, 2011) dizem que ao contrário do processo de outsourcing, os serviços compartilhados podem padronizar e consolidar funções comuns dentre múltiplas organizações para reduzir o processo de duplicação de informações, tal como aumentar a disseminação de conhecimentos e informações. Isso indica que os CSCs conseguem ir mais além das empresas contratadas no mercado via-outsourcing e oferecer um serviço mais específico à organização em termos de entrega de serviços especializados para a matriz e as subsidiárias de uma grande companhia.

\section{Metodologia}

\subsection{Classificação da Pesquisa}

Segundo Marcones e Lakatos (2003), "pesquisar é encontrar respostas para questões propostas, utilizando métodos científicos". Para que uma pesquisa científica seja avaliada como confiável e alcance os objetivos a que se destina, é indispensável à definição da metodologia a ser utilizada, buscando gerenciar os procedimentos de maneira coerente e organizada facilitando o trabalho a ser realizado.

Do ponto de vista de sua natureza será realizada uma pesquisa aplicada que segundo Silva e Menezes (2001, p. 20), "objetiva gerar conhecimentos para aplicação prática dirigida à solução de problemas específicos, envolvendo verdades e interesses locais".

Do ponto de vista da forma de abordagem do problema a metodologia utilizada será a pesquisa qualitativa, visando às características e a natureza do problema a ser estudado. Para Silva e Menezes (2001, p. 20), uma pesquisa qualitativa considera que há uma relação dinâmica entre o mundo real e o sujeito, isto é, um vínculo indissociável entre o mundo objetivo e a subjetividade do sujeito que não pode ser traduzida em números. Não requer o uso de métodos e técnicas estatísticas e será descritiva. O processo e seu significado são os focos principais da abordagem.

Do ponto de vista de seus objetivos, será realizada uma pesquisa exploratória, que visa elaborar um modelo de avaliação de nível de serviços para um Centro de Serviços Compartilhados (CSC), para empresas que atuam na área de comércio varejistas. Segundo Gil (2002), a pesquisa exploratória visa proporcionar maior familiaridade com o problema com vista a torná-lo explícito ou a construir hipóteses. Envolve levantamento bibliográfico; entrevistas com pessoas que tiveram experiências práticas com o problema pesquisado; análise de exemplos que estimulam a compreensão.

Do ponto de vista dos procedimentos técnicos, será desenvolvida uma pesquisa bibliográfica, "elaborada a partir de material já publicado, constituído principalmente de livros, artigos de periódicos e eventos e atualmente com material disponibilizado na internet" (GIL, 2002). Para que seja reunido todo material necessário para alcançar os objetivos propostos.

Em paralelo, a presente pesquisa também pode ser classificada como estudo de caso: "quando envolve o estudo profundo e exaustivo de um ou poucos objetos de maneira que se permita o seu amplo e detalhado conhecimento" (GIL, 2002). 


\subsection{Pesquisa Metodológica}

Coelho et al. (2013), realizaram pesquisa semelhante em Minas Gerais, a unidade de análise foi o Poder Executivo do Estado de Minas Gerais, durante o ano de 2010, com o objetivo de desenvolver um modelo de gestão de Centro de Serviços Compartilhados para uso em organizações tanto públicas quanto privadas. O tipo de procedimento é o estudo de caso, com amostragem não-probabilística por acessibilidade. A coleta de dados ocorreu por meio de entrevista com questionário semi-estruturado e aplicação de cartões de Preferência Declarada.

Affonso (2010) prefere realizar a pesquisa através do método de estudo de casos múltiplos, em duas empresas localizadas em Minas Gerais, uma em Uberlândia e a outra em Poços de Caldas. Este trabalho trata de uma investigação que se utilizou de entrevista semi-estruturada, realizada pessoalmente nas sedes das empresas. Para analisar os impactos da implementação de Centro de Serviços Compartilhados - CSC na estratégia, na estrutura e na gestão de empresas do setor privado que já possuam o modelo consolidado, com a abordagem sobre a forma empregada de terceirização (interna e externa) para execução dos serviços compartilhados.

Gonçalves (2005) concebeu a revisão bibliográfica através do levantamento de alguns estudos existentes no Brasil, e também no exterior. Em relação ao estudo de caso único, este foi desenvolvido em uma empresa multinacional de origem europeia, e tem por objetivo verificar se os gestores estavam satisfeitos com as informações recebidas, bem como se a prestação destes serviços auxilia o processo de tomada decisão dos referidos gestores. O estudo foi desenvolvido entre os anos de 2004 e 2005.

\subsection{Procedimentos Técnicos}

O arcabouço teórico, que dá a sustentação para o estudo de caso, será construído a partir de pesquisa bibliográfica nas principais bases científicas brasileiras, por meio de consulta eletrônica no portal de buscas acadêmicas Google Scholar@ .

A coleta de dados se dá em dois momentos. O primeiro momento em uma entrevista semi-estruturada, cujas questões direcionadoras estão no Anexo I deste trabalho, com objetivo de caracterizar os objetos de estudo, tipar o Centro de Serviço Compartilhado utilizado pelas unidades e identificar as áreas em que o CSC é presente.

O segundo momento por meio da aplicação de um questionário entregue em mãos aos colaboradores de nível tático das unidades pesquisadas, sendo que no momento da entrega, uma pequena explanação foi feita de modo a sanar as dúvidas mais frequentes. A coleta dos dados começou em 21/09 do ano corrente, e encerrou-se no 08/10.

\subsection{População \& Amostra}

A população de interesse deste trabalho compreende nos funcionários de nível tático das organizações dos estudos de caso múltiplos, que são clientes dos Centros de Serviço Compartilhados. As empresas pesquisadas são da área do comércio varejista, localizada em Campos dos Goytacazes, no norte do estado do Rio de Janeiro.

A amostragem é definida, segundo Silva e Menezes (2001, p. 32) por técnica não probabilística, intencional, aonde o questionário é entregue em mãos ao gerente da unidade de negócio, assumido por premissa como principal conhecedor dos seus processos. 


\subsection{Instrumento de Interrogação}

O questionário utilizado foi adaptado de Coelho et al. (2013), de onde foram considerados os itens a serem avaliados (Atendimento, Confiabilidade e Entrega). As grandes áreas a serem avaliadas foram elaboradas a partir do cruzamento da bibliografia consultada sobre o CSC e as entrevistas realizadas.

O instrumento de interrogação utilizado esta disponível em Anexo ao final deste documento.

\subsection{Técnica de análise dos resultados}

A partir de perguntas fechadas (dicotômicas e de múltipla escolha), o questionário permite avaliar a qualidade dos serviços executados pelo CSC e identificar possíveis pontos críticos e deficiências nas atividades realizadas, com a finalidade de balizar as tomadas de decisões dos gestores e assim proporcionar melhorias das atividades de apoio da empresa. O questionário aplicado encontra-se em Anexo ao final deste trabalho.

Os dados coletados são tabulados em planilha eletrônica, sumarizados por item e agrupadas por dimensão, de onde é possível apurar o grau de concordância/discordância da população investigada, e a frequência de cada item da escala de resposta. Sendo assim é realizada a análise e interpretação dos resultados.

As respostas foram associadas a uma escala numérica, como segue, para cálculos de média:

- 1: Não Concordo com Nada;

- 2: Não Concordo Parcialmente;

- 3: Indiferente;

- 4: Concordo Parcialmente;

- 5: Concordo Absolutamente com Tudo.

\section{Estudos de caso múltiplos}

\subsection{Caracterização dos objetos de Estudo}

A presente pesquisa foi desenvolvida em duas empresas atuantes no segmento varejista que possuem CSC consolidado. Devido a dificuldades de acesso a todas as lojas das organizações estudadas, a coleta de dados foi realizada nas lojas localizadas em Campos dos Goytacazes, no norte do estado do Rio de Janeiro.

\subsubsection{Caso 1}

A empresa XPTO foi fundada em 1929, na cidade de Niterói, no Rio de Janeiro, por um grupo de norte-americanos, que decidiram abrir sua primeira loja no Brasil, por perceberem que na época não havia no país lojas de departamentos - uma loja de preços baixos e que vendesse vários tipos de mercadorias. Eles desejavam oferecer uma maior variedade de produtos a preços mais acessíveis.

Atualmente organização tem sua sede na cidade do Rio de Janeiro, e conta com quatro centros de distribuição em: Nova Iguaçu (Rio de Janeiro), Barueri (São Paulo), Brasília (Distrito Federal) e Recife (Pernambuco). É composta por 760 estabelecimentos de vendas em 22 estados do país e 
também no Distrito Federal, que comercializa mais de 240 mil itens, atuando no mercado com o estilo de auto-atendimento.

As unidades de negócio da empresa são organizadas por regiões distritais, sendo que na cidade de Campos dos Goytacazes são localizadas três lojas, as mesmas fazem parte do Distrito de Niterói, que é composta por 41 lojas. Sendo assim, é a quarta maior empresa varejista do Brasil.

\subsubsection{Caso 2}

A empresa XPTY foi fundada em 1951, na cidade de Miracema, no interior do estado do Rio de Janeiro, no início de sua trajetória era um bazar que atraia clientes de toda a região com a venda de calçados a quilo. Nos dias de hoje, a administração da organização é localizada em Niterói.

Além disso, atua nos estados de Minas Gerais, Bahia, Pernambuco, Espírito Santo, Rio de Janeiro, Alagoas, Sergipe e Rio Grande do Norte, contando com uma rede de 82 lojas de departamentos, com duas filiais em Campos dos Goytacazes, e emprega aproximadamente 5.000 pessoas, possuindo um centro de distribuição com mais de $17.000 \mathrm{~m}^{3}$.

\subsection{Resultados}

A Figura 5 representa a média geral dos resultados, e apresenta a seguinte distribuição: $42,9 \%$ da área de logística; $42,9 \%$ da área de recursos humanos; $71,4 \%$ da área de tecnologia da informação; $82,1 \%$ da área de marketing e 53,6\% da área de finanças concordam plenamente com as diversas afirmações sobre a qualidade dos serviços compartilhados prestados pelo CSC.

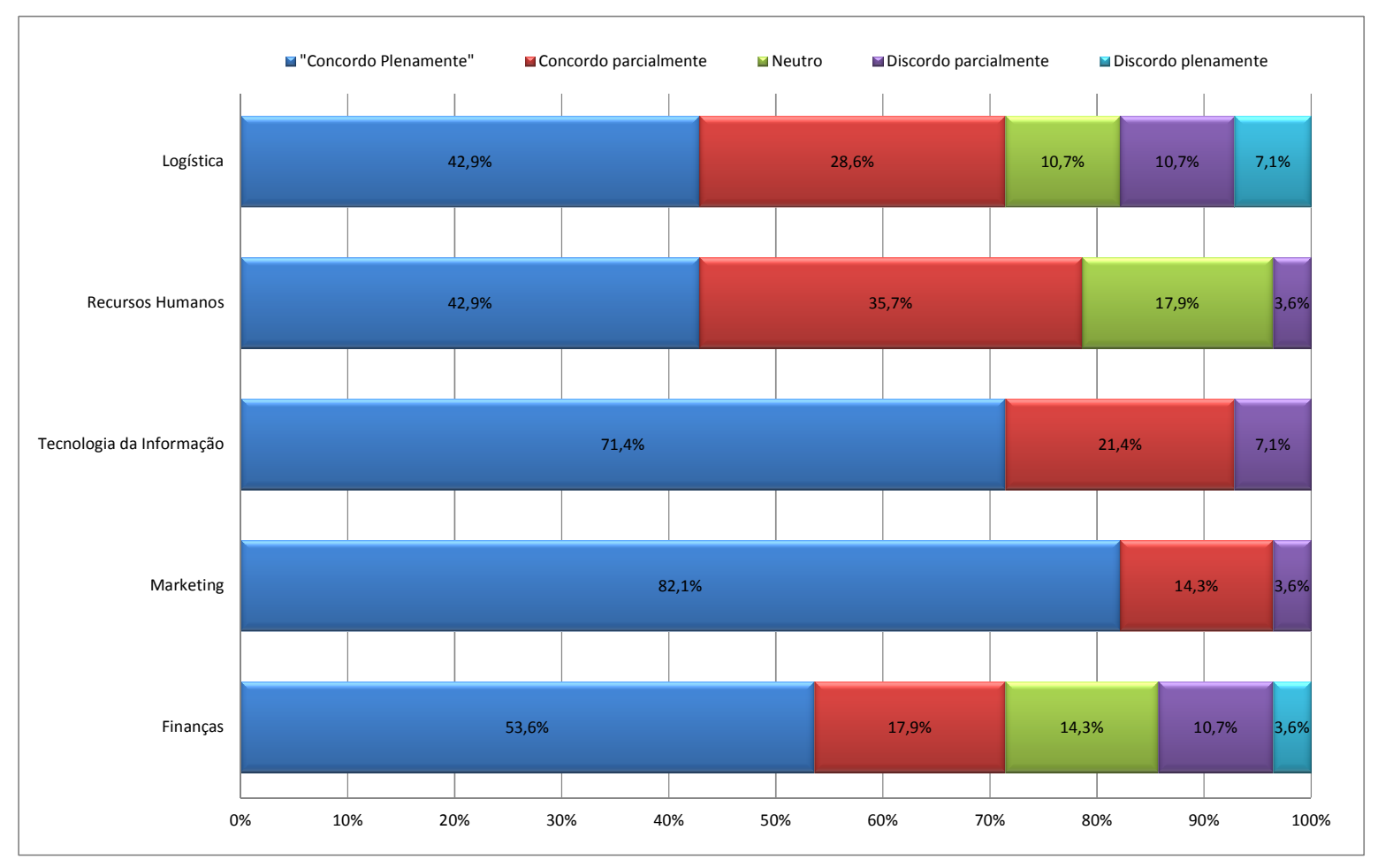

Figura 1: Resultado geral. 
Pode ser observado na Figura 5, que os serviços compartilhados de logísticas, recursos humanos e finanças não atendem totalmente as demandas de seus clientes internos (as lojas), assim sendo as respectivas áreas apresentam falhas e deficiências em alguns aspectos das atividades avaliadas no presente estudo. Essas grandes áreas requerem medidas corretivas, para assim maximizar todos os benefícios esperados com a implementação do CSC.

Já as áreas de tecnologia da informação e marketing são qualificadas como satisfatórios, pois apresentam um bom desempenho de acordo com percepção dos gestores inquiridos. Apesar de tal avaliação, foram identificados alguns pontos dos serviços que devem ser aprimorados, e desta maneira possibilitar a organização alcançar a excelência operacional em suas atividades de apoio.

A Figura 6 apresenta a síntese dos resultados. A primeira linha de cima para baixo de todos os gráficos da Figura 6 representam a logística, e seguindo a ordem, recursos humanos, tecnologia da informação, marketing e finanças. As respectivas grandes áreas são classificadas pelas unidades pesquisadas como atividades de apoio a organização, sendo assim tais serviços são designados ao CSC. Já a legenda de cores representa o grau de concordância da população inquirida em relação à qualidade dos serviços prestados pelo CSC. Onde a legenda é composta pelas cores azul escuro, vermelho, verde, roxo e azul claro, sendo respectivamente categorizadas como concordo plenamente, concordo parcialmente, neutro, discordo parcialmente e discordo plenamente. 


\section{PERSPECTIVAS online}

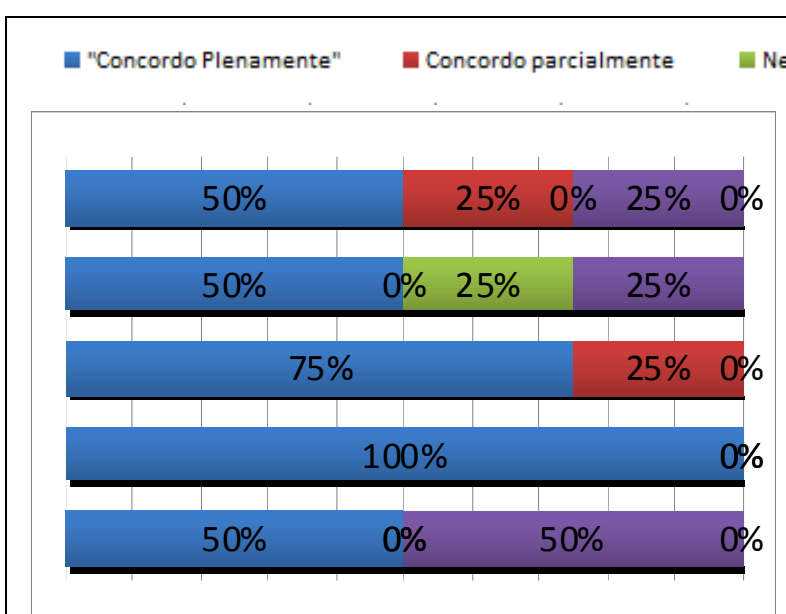

(a)

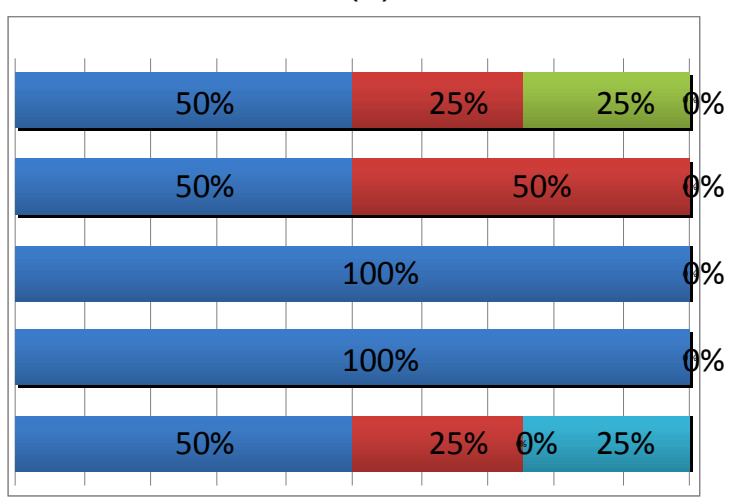

(c)

\begin{tabular}{|c|c|c|}
\hline $50 \%$ & $25 \% \quad 0 \%$ & $25 \%$ \\
\hline $75 \%$ & $0 \%$ & $25 \%$ \\
\hline $75 \%$ & $0 \%$ & $25 \%$ \\
\hline $75 \%$ & & $25 \%$ \\
\hline $75 \%$ & $0 \%$ & $25 \%$ \\
\hline
\end{tabular}

(e)

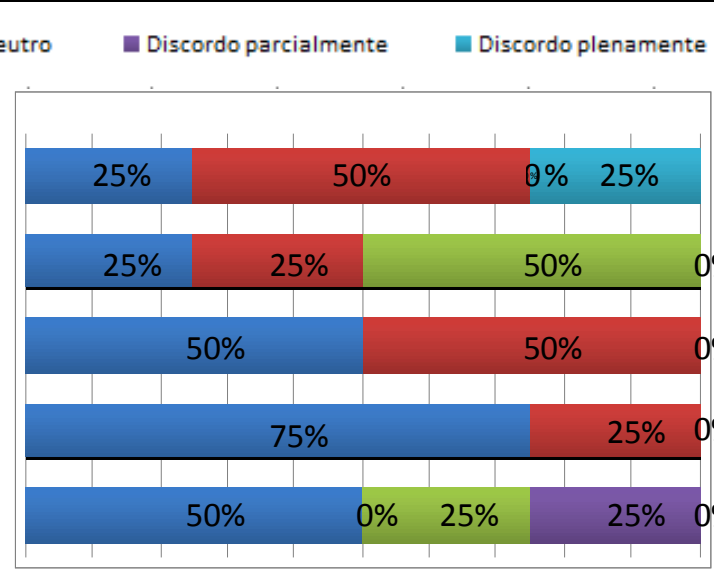

(b)

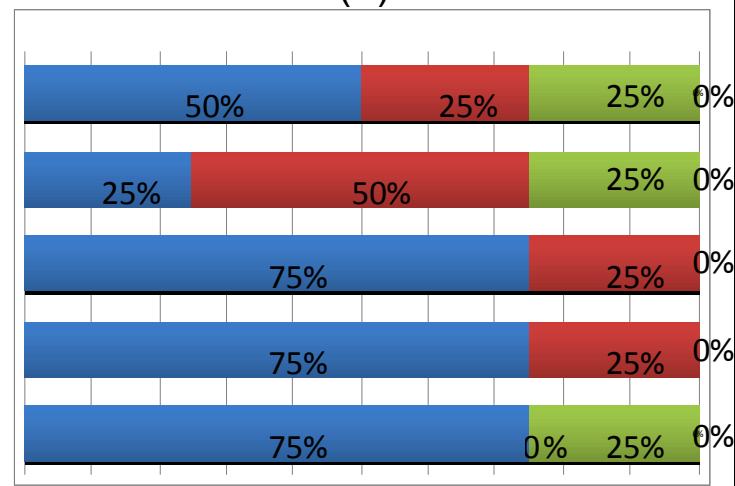

(d)

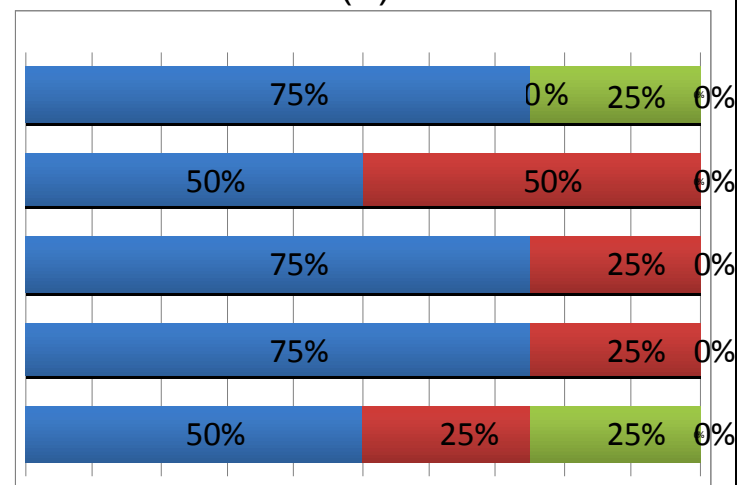

(f)

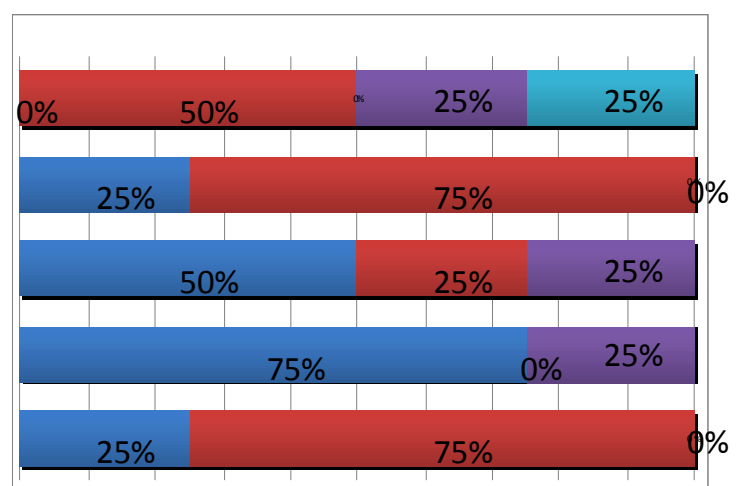

(g) 
Figura 6.a, é possível ressaltar que as atividades de suporte executadas pela área de marketing são avaliadas como excelentes, sendo que $100 \%$ da população pesquisada concorda plenamente que o tempo de resposta a solicitações de informações ou reclamações é rápido. Entretanto em relação aos serviços de finanças, $50 \%$ dos investigados discordam parcialmente da afirmação, esse resultado evidencia a necessidade de agilizar o tempo de resposta às dúvidas e interrogações dos gestores e colaboradores das lojas.

A Figura 6.b, a linha que representa a logística, apresenta a seguinte distribuição, apenas $25 \%$ dos respondentes concordam plenamente que a entrega dos pedidos é rápida, $50 \%$ concordam parcialmente e $25 \%$ discordam plenamente da afirmação, tais resultados identificam possíveis falhas na execução dos serviços de ressuprimento da organização, apresentando assim a necessidade de melhorias em seus processos.

No caso da Figura 6.c, verifica-se que $100 \%$ da população investigada concordam plenamente que os serviços compartilhados das áreas de tecnologia da informação e marketing atendem as demandas das lojas com precisão, desta forma as atividades de suporte alcançaram a excelência operacional, pois segundo o ponto de vista da gerência das unidades pesquisadas, obteve-se êxito em todo o processo.

Como pode ser verificado da Figura 6.d, os serviços compartilhados de recursos humanos são avaliados como pouco satisfatório em relação a um dos quesitos do item confiabilidade, pois $50 \%$ dos inquiridos concordam parcialmente que possuem suas solicitações completamente atendidas, $25 \%$ são neutros, e apenas $25 \%$ concordam plenamente com a afirmação. Sendo assim a área analisada requer um plano de correção e aprimoramento para resolver suas falhas.

Ainda pode ser observado na Figura 6.d, que 75\% dos respondentes concordam plenamente que não há ocorrência de erros na entrega das demandas solicitadas nas áreas de tecnologia da informação, marketing e finanças, tais resultados demonstram que os gestores das unidades estudadas avaliam como satisfatórios os serviços.

No caso da Figura 6.e, pode-se analisar que as atividades realizadas pelas área de recursos humanos, tecnologia de informação, marketing e finanças são qualificados como confiáveis, tal afirmação é comprovada pelo fato de que $75 \%$ dos respondentes concordarem plenamente que sabem ao certo o momento que terão suas demandas atendidas pelas respectivas áreas avaliadas.

No caso da Figura 6.f, observa-se que $75 \%$ da população inquirida concorda plenamente que o atendimento é totalmente padronizado e que as atividades executadas pelo CSC das áreas de logística, tecnologia da informação e marketing possuem rigorosamente o mesmo padrão e a mesma qualidade em todas as lojas do país. Desta forma o desempenho dos serviços analisados é considerado satisfatório de acordo com a percepção dos gestores entrevistados.

Na Figura 6.g, verifica-se que os serviços compartilhados de Finanças e Recursos Humanos representam um problema grave a ser enfrentado pela gestão, pois pode se observar que $75 \%$ da população investigada concorda parcialmente que o CSC atende as expectativas da loja, possibilitando pedidos facilitados e confirmação ágil, tal resposta evidência que os inquiridos estão insatisfeitos em relação a alguns quesitos das atividades realizadas. 


\section{Conclusões}

\subsection{Quanto aos objetivos}

Este estudo baseou-se na avaliação do grau de desempenho dos serviços prestados pelo CSC, segundo a percepção de seus clientes internos. Na execução dos estudos de caso múltiplos, foi possível aplicar um instrumento de interrogação adaptado pelo presente trabalho, em organizações do segmento varejista, que possuem filiais atuantes na cidade de Campos dos Goytacazes.

O objetivo geral do trabalho é alcançado, visto que foi adaptado um modelo de avaliação, onde os itens (Atendimento, Confiabilidade e Entrega) e as grandes áreas a serem analizadas foram fundamentadas a partir de criteriosas pesquisas bibliográficas sobre CSC e entrevistas realizadas.

\subsection{Quanto ao trabalho realizado}

A utilização de métodos que avaliem o grau de desempenho dos serviços compartilhados é uma prática benéfica à gestão do CSC, pois monitoram a qualidade das atividades não-core da empresa. Sendo assim, tais avaliações podem e devem ser utilizadas para melhorar a gestão CSC, já que permitem o controle das atividades, a identificação de pontos críticos e as possíveis soluções.

Também é importante ressaltar, que os estudos da área de Administração tendem a buscar maior compreensão sobre as atividades core das organizações, de forma que são realizados em menor proporção estudos sobre o gerenciamento das atividades não-core, pode-se então concluir que a maneira pela qual elas podem agregar valor e competitividade a organização são menos exploradas. $\mathrm{O}$ presente estudo acrescenta mais considerações sobre este relevante o tema.

O instrumento adaptado e validado nesta pesquisa foi utilizado para avaliar a qualidade dos serviços compartilhados de cinco grandes áreas das unidades inquiridas, as respectivas áreas são: logística, recursos humanos, tecnologia da informação, marketing e finanças.

As análises demonstraram que os serviços de logística, recursos humanos e finanças não supriram totalmente as necessidades das lojas, pois suas demandas são atendidas com algumas deficiências. Diante de tais verificações, orienta-se a gestão elaborar um plano de ação objetivando a melhoria dos processos que apresentaram falhas.

Já os serviços compartilhados de tecnologia da informação e de marketing são avaliados como satisfatórios, as respectivas áreas apresentam um elevado nível de desempenho de acordo com a percepção dos administradores inquiridos. Entretanto, foram identificados alguns aspectos nos serviços avaliados que podem e devem ser aprimorados, para assim alcançar a excelência operacional.

Evidenciou-se nessa pesquisa, que avaliação das atividades não-core, é uma prática fundamental para a gestão do Centro de Serviços Compartilhados, pois proporciona um controle dos processos centralizados para que seja garantido um alto nível de qualidade dos serviços. 


\subsection{Quanto aos trabalhos futuros}

O método adaptado e validado neste presente estudo pode ser reaplicado em outras organizações, não apenas em empresas do segmento de varejo, mas também de outras segmentações, realizando comparativos com este estudo.

A expansão da pesquisa, que foi realizada em somente uma pequena amostra da rede, pode ser executada em outras um território maior, de modo a comparar os serviços entre capital e interior, entre estados, ou estratificando os dados por maturidade do colaborador do nível tático, expondo seu poder de negociação com o CSC de acordo com o tempo de serviço na empresa.

\section{Referências}

AFFONSO, José Henrique. Centros de Serviços Compartilhados (CSC): Impactos da implementação do Modelo na Estratégia, na Estrutura e na Gestão de empresas do setor privado. 2010. Dissertação (Mestrado) - Universidade FUMEC, Belo Horizonte, 2010.

Disponível em:

$<$ http://www.fumec.br/anexos/cursos/mestrado/dissertacoes/completa/henrique_jose_affonso. pdf>. Acesso em: 22 mar.2013.

COELHO, Renata; MARTINS, Ricardo; LOBO, Débora. Desenvolvimento de modelo de avaliação de aplicação a um Centro de Serviços Compartilhados. 2013. 12 p. Revista Portuguesa e Brasileira de Gestão, vol. 12, nº. 1, Lisboa, jan. 2013.

CUNHA, Júlio Araújo Carneiro. A gestão de pessoas em centro de serviços compartilhados no Brasil: Um estudo sobre a percepção dos gestores e empregados operacionais. 2011. Tese (Doutorado) - Fundação Getúlio Vargas Escola de Administração de empresas de São Paulo, São Paulo, 2011. Disponível em: <http://bibliotecadigital.fgv.br/mwginternal/de5fs23hu73ds/progress?id=2CrR8UONC7>. Acesso em: 27 mar. 2013.

DELOITTE, Tohmatsu Touche. Centralizar para crescer: Rumo à Excelência em Centros de Serviços Compartilhados. 2007. Disponível em: $<$ http://www.deloitte.com.br/publicacoes/2007/Centro_Servicos_Compartilhados.pdf $>$.

Acesso em: 25 mar. 2013.

DELOITTE, Tohmatsu Touche. Centro de Serviço Compartilhado: Tendências em um Modelo de Gestão cada vez mais comum nas organizações. 2007. Disponível em: $<$ http://www.deloitte.com/assets/Dcom-

Brazil/Local\%20Assets/Documents/Centros\%20de\%20Servios\%20Compartilhados\%20(2007 .pdf>. Acesso em: 25 mar. 2013.

GIL, Antônio Carlos. Como elaborar projetos de pesquisa. São Paulo: Editora Atlas, 2002.

GONÇALVES, Márcio Antônio. Serviços Compartilhados: Um estudo de caso da área de controladoria no Brasil em uma empresa de vitaminas compartilhando serviços para 
alguns países da América Latina. 2005. Dissertação (Mestrado) - Centro Universitário Álvares Penteado - UNIFECAP, São Paulo, 2005. Disponível em: $<$ http://200.169.97.106/biblioteca/tede/tde_arquivos/3/TDE-2010-03-15T175515Z213/Publico/Marcio_Antonio_\%20Goncalves.pdf $>$. Acesso em: 02 abr. 2013.

MARCONI, Marina de Andrade; LAKATOS, Eva Maria. Fundamentos de metodologia científica. São Paulo: Editora Atlas, 2003.

RAMOS, Luciano José Trindade. Serviços compartilhados como forma de estruturação organizacional. 2005. 128p. Dissertação (Mestrado em Administração) UFBA/ Escola de Administração 2005.

Disponível em:<http://www.adm.ufba.br/sites/default/files/publicacao/arquivo/003.pdf $>$. Acesso em: 27 mar.2013.

SCHULMAN, Donniel S. e outros. Shared Services: Serviços Compartilhados. São Paulo: MAKRON Books, 2001.

SILVA, Eduardo Damião da; PEREIRA, Neuri Amábile Frigotto. Centro de serviços compartilhados e a gestão de vínculos: uma análise integrada. 15 p. Revista Alcance UNIVALI - Vol.11 - n.1 p. 49 - 64, Jan./Abr. 2004.

SILVA, E. L. S.; MENEZES, E. M. M. Metodologia da Pesquisa e Elaboração de Dissertação. 4. ed. Florianópolis: UFSC, 2001.

SOUZA, Marcos Antônio de; CORRÊA, Rodrigo Machado. Centros de Serviços Compartilhados: Publicações no Congresso Brasileiro de Custos (CBC) no Período de 1998 a 2008. 2010. 33p. Revista Contabilidade Vista \& Revista Universidade Federal de Minas Gerais, Belo Horizonte, v.22, n. 1, p. 73-105, jan./mar. 2011.

SOUZA, Moisés de; MELIM, José Maria; MACEDO, Marcelo. O estudo da eficácia do modelo CSC em uma instituição privada do ensino superior geograficamente distribuída. 12 p. II Congresso Brasileiro de Engenharia de Produção, nov. 2012. 


\section{ANEXO 1: QUESTIONÁRIO}

As questões seguintes referem-se aos atributos/dimensões dos Serviços do Centro de Serviços Compartilhados (CSC), nas seguintes áreas: Financeira, Marketing, Tecnologia da Informação, Recursos Humanos e Logística. Responda o questionário abaixo de acordo com sua percepção em relação à qualidade dos serviços prestados pelo CSC.

Na coluna onde está destacado CONCORDÂNCIA, marque a nota que melhor representa sua percepção sobre a satisfação com os serviços nos aspectos (atributos), sendo: [1] Não Concordo com Nada; [2] Não Concordo Parcialmente; [3] Indiferente; [4] Concordo Parcialmente; [5] Concordo Absolutamente com Tudo.

\begin{tabular}{|c|c|c|c|c|c|c|}
\hline & & Financeiro & Marketing & $\begin{array}{c}\text { Tecnologia } \\
\text { da } \\
\text { Informação } \\
\end{array}$ & $\begin{array}{l}\text { Recursos } \\
\text { Humanos }\end{array}$ & Logística \\
\hline & & \multicolumn{5}{|c|}{ CONCORDÂNCIA } \\
\hline & & \begin{tabular}{l|l|l|l|l}
1 & 2 & 3 & 4 & 5 \\
\end{tabular} & \begin{tabular}{|l|l|l|l|}
1 & 2 & 3 & 4 \\
\end{tabular} & \begin{tabular}{l|l|l|l|l|l}
1 & 2 & 3 & 4 & 5 \\
\end{tabular} & \begin{tabular}{|l|l|l|l|}
1 & 2 & 3 & 4 \\
\end{tabular} & \begin{tabular}{l|l|l|l|l} 
& 2 & 3 & 4 & 5 \\
\end{tabular} \\
\hline & $\begin{array}{l}\text { O CSC atende as expectativas da loja, alcançando a excelência na qualidade dos } \\
\text { serviços, sendo assim os pedidos são facilitados e a confirmação é ágil. }\end{array}$ & & & & & \\
\hline Atendimento & $\begin{array}{l}\text { O atendimento é totalmente padronizado, os serviços são realizados conforme as } \\
\text { especificações solicitadas. }\end{array}$ & & & & & \\
\hline \multirow{3}{*}{ Confiabilidade } & $\begin{array}{l}\text { O atendimento é confiável, os clientes sabem ao certo o momento em que terão suas } \\
\text { demandas atendidas, os prazos estipulados são plenamente cumpridos. }\end{array}$ & & & & & \\
\hline & $\begin{array}{l}\text { Os pedidos entregues têm suas solicitações completamente atendidas (especificações, } \\
\text { quantidade e sortimento), não há ocorrência de erros. }\end{array}$ & & & & & \\
\hline & $\begin{array}{l}\text { As necessidades das unidades de negócio são atendidas com precisão, desta forma os } \\
\text { serviços são entregues sem avarias. }\end{array}$ & & & & & \\
\hline & $\begin{array}{l}\text { A entrega é rápida, correspondendo aos ciclos de pedidos (período entre a efetivação } \\
\text { do pedido e a entrega dos itens ou inicialização dos serviços). }\end{array}$ & & & & & \\
\hline Entrega & O tempo de resposta a solicitações de informações ou reclamações é rápido. & & & & & \\
\hline
\end{tabular}

